\title{
A study on the necessity and implementation strategies of university archive service innovation in information era
}

\author{
Shumin Cui \\ Management of teaching and research base, \\ Jilin Agricultural University, \\ Changchun, China \\ Email: cuishuminc@126.com
}

Key words: university archive service, innovation, necessity, implementation strategies

\begin{abstract}
The value and significance of archives is achieved through social service. Serviceability is the basis for the survival and development of university archives. The service mechanism innovation of university archive is the inevitable request for information society development, the inevitable request for higher education reform, and the inevitable request for university archive's own development. This paper explores the university archival management based on the service consciousness and summarizes the necessity of university archive service innovation at the present stage. It also puts forward reasonable strategies to enhance service awareness and strengthen university archives management in order to further promote the development of university archives management.
\end{abstract}

\section{Introduction}

In the information age, the rapid development of university information construction and the construction and operation of various information systems have greatly enhanced the speed and efficiency of information flow of universities. University archives information has become an important direction for the development of university archives. It is an important means to scientifically manage archives and the imperative to realize the modernization of university archives management. However, the traditional service model of manual collection, sorting, use of archives, which is still used nowadays, cannot meet the needs of customers. It radically restricts the improvement of archive service capabilities, resulting in the development of university archives information technology has significantly lagged behind the requirements of the information age, which forces us to consider the model transformation of archives service. Faced with the challenges, the university archivists must respond positively and constantly update the old ideas. Realize the transformation from traditional mode to modern mode through the innovation of service mechanism. In order to keep pace with the information age, we must actively carry out the network delivery service of archive information.

\section{The necessity of university archive service innovation}

A. Innovation of university archives services is an inevitable requirement of the development of information society

As the pivot of collecting, collating, storing, processing, and disseminating knowledge and information, innovation archives are more sensitive to the impact of information technology and networking wave. The sharp increase in the amount of knowledge and information leads to the increase of the amount of archive as the most basic part among various information resources in the information society. The archive content becomes richer and the archive carrier is increasingly diverse. The corresponding file collection, sorting, identification, statistics, classification, storage 
and utilization of archives and other information technology services will also have a huge change. These result in tremendous changes in traditional service system and service manner of archives striding forward towards the direction of socialization, digitization, networking and individuation.

\section{B. Innovation of university archives services is an inevitable requirement of the reform of higher education}

The gradual deepening of the current reform of higher education leads to colleges and universities transforming from the original affiliated government units to legally independent school facing to society under the government macro-control. The internal school mechanism changes from the form of government counterparts into abiding by the education regulation settings. The relationship between school and teachers, school and students also changes from the original administrative relationship into a contract relationship. Schools must adapt to the laws and rules of market economy, weaken the executive management, enhance service awareness, and improve service levels.

Development and reform of higher education propose the corresponding requirements to the post management of university archives department, human resources strategy, network services, service orientation, resource sharing and other functions. The requirements include establishing public service system like education and research high-speed network, high-quality educational resources, building advanced information technology platform of higher education, and realizing high-quality education and information sharing. Under this background, university archive departments should take archives information services into university education resources and public service system for construction revolving around higher education and school reform. Keep improving information service connotations and realizing value-added archive information to serve school teaching, research and other work. Only by giving full play to the value of university archives, the status of university archives department can be solved fundamentally. The university archives must pay close attention to higher education reform and study the impact of higher education reform on archival work and the new requirements proposed. Reset the archive ideas and objectives fitting for the development demand of higher education and strive to reform service mechanism on the basis of higher education reform. Make adjustments on concept, institution, management, and service to adapt to the new management model. Improve and expand the service function of archives department on this basis so as to be more proactive in serving universities and society and meet the needs of reform and development of higher education fundamentally.

\section{Innovation of university archives services is an inevitable requirement of the development of university archives}

As one of the services sector of universities to carry out information service, university archives will develop in the direction of information archive and integrate information collection, dissemination, management, service, and other functions into a whole union. Combine the collection of electronic documents and the traditional printed archival material to fit the requirements of information society to university archives and become archival information resource center.

\section{Raise service awareness and strengthen the rational strategies of the management of university archives}

\section{A. Strengthen the work ethic and education for sense of responsibility of archives management staff of university}

In order to improve the work efficiency of university archive management, the first thing should be strengthened is the work ethic and sense of responsibility of archives management staff of university. Only the archive management staffs are clearly aware of the importance of their work tasks and their responsibilities, can they get rid of the lazy service awareness at work. Then they can provide archive management services to teachers and students proactively and improve work efficiency through various means. They can also shorten the time required to inspect the file 
information of teachers and students and improve the efficiency of teachers and students' access to archives and shine in their own work.

\section{B. Perfect the archives management system and strengthen supervision}

The management work of university archives should establish a sound system of work which includes the collection mode of archives, the quality evaluation mode of archives, the service model provided by archive information, and the regulatory model of archive management staff. By different modes of management system of university archive, hierarchical and ordered archival management can be formed, thus improving the quality of file management services. Moreover, the supervision of archive management needs to be reinforced and the previous ignorance of university management personnel to archives management needs to be corrected too by taking proper and reasonable management measures to promote the progress of archives management.

\section{Make innovations on service ideas and service mode of university archival management}

The service ideas and service mode of university archival management should be continuously perfected and reformed. Firstly, the understanding of archive management staff to the service needs to be strengthened. Secondly, some advanced form of university services should be demonstrated to archive management staff. Thirdly, the improvement requirements of service for archive management staff should be clearly stated to promote the idea of service to be perfect. Make innovations on the service mode of archives management and get rid of a single artificial lookup service. Use computer technology and network information technology and design and provide services such as archive data sharing and public education in order to gain the recognition and love of teachers and students in the service manner.

\section{Increase the exchange of experience and learning of domestic and foreign universities archival management service}

Compared with domestic work in this area, foreign universities archival management is far ahead of the domestic universities. This is mainly because foreign universities value archive management work and they regard the school's development and archives as an honor. They encourage teachers and students to view and collect the archives enrich the collection and enrich the collection. Besides, there are plenty of managers in foreign universities to carry out archive management, classification order, guidelines consultation, information input and resource sharing services, which cannot be reached in domestic universities. Therefore, we need to increase the exchange of experience and learning of domestic and foreign universities archival management service and draw on the strong points of others to make up for our own weak points. Constantly improve the service ideas and innovative services of domestic university archive management and secure the proper and order conduct of archival management from the aspects of human resources and information resources.

\section{E. Increase capital investment and improve the hardware level of university archives management}

Of course, if we only discuss the improvement of service quality of university archival management theoretically, and ignore the actual work and corresponding service facilities, everything is empty talk and brings no effective driving force to the efficiency of university archival management and the improvement of job quality. Therefore, universities should combine the actual situation of their own development and increase capital investment reasonably to improve the hardware level of university archives management, such as the building of records storage, the disinfection and preservation of archival material, the archives ventilation facilities and computer equipment and so on. Only the hardware conditions are met, can the theoretical idea of service is used so as to provide better archive management services to teachers and students. 


\section{Conclusion}

The value and significance of archives are achieved through social service, which determines the ultimate goal of archives management is to maximize the development and utilization of archival information resources and serve human social activities and social practice. University archival management service is the basis for the survival and development of university archives and it is also a revolution. Archivists must meet the challenge to meet the needs of archive information services and focus on the need of continual development of archival work. They also need to learn new technologies and improve the ability to manage modern technology and actively explore ways of the construction of digital archives. However, if we only regard archives as places to read and save files and maintenance of traditional archives service, it is not conducive to maximizing the social and economic benefits of university archives information resources and not conducive to realizing sharing of information resources. So university archive service must innovate. Currently, the digitization, document processing integration, information transmission network, intelligent management system, and professional staff, are the requirements of expanding the university archives information service.

\section{References}

[1] Xiong Youju. Challenges of the information society to the traditional pattern of archive information service[J]. Archives Science Bulletin, 2011 (5):91-93.

[2] Liu Haiyan. Discussion on Problems and Countermeasures existing in university archival management[J]. Science \& Technology Information, 2011, (2).

[3] Yan Dehua. Opinions on improving the quality of archive personnel and university archive[J]. Journal of Qinghai Normal University (Natural Science Edition), 2013, (1) .

[4] Peng Guoyun. Research on university archive service under socialization[D]. East China University Of Political Science And Law, 2012.

[5] Qi Junbao, Luo Linfang. Enlightenment and Reference of Foreign archives social service functions innovation to China[J]. Lantai World, 2009,(18):14 - 15. 